\title{
Management of Pleural Effusion After Mediastinoscopic Radical Esophagectomy
}

\author{
JUNICHI HAMADA, HIROTAKA KONISHI, ATSUSHI SHIOZAKI, HITOSHI FUJIWARA, KATSUTOSHI SHODA, \\ TOSHIYUKI KOSUGA, TAKESHI KUBOTA, KAZUMA OKAMOTO, TOMOHIRO ARITA, RYO MORIMURA, \\ YASUTOSHI MURAYAMA, HISASHI IKOMA, YOSHIAKI KURIU, MASAYOSHI NAKANISHI and EIGO OTSUJI
}

\author{
Division of Digestive Surgery, Department of Surgery, Kyoto Prefectural University of Medicine, Kyoto, Japan
}

\begin{abstract}
Background/Aim: Trans-hiatal and -cervical approach mediastinoscopic radical esophagectomy (TMrE) for esophageal cancers is a less-invasive procedure and does not require for trans-thoracic approach management. However, some patients suffer from pleural effusion after TMrE. In the present study, we investigated the clinicopathological factors of patients needing drainage of pleural effusion (DPE) after TMrE. Patients and Methods: This study included 118 patients who underwent TMrE between 2010 and 2016. Results: There were 43, 34 and 41 patients that underwent none, a single, and two or more DPEs respectively. Left-side DPE was significantly more frequent compared to right-side DPE. Change in the C-reactive protein (CRP) levels after surgery was significantly higher in patients with multiple DPEs than patients with none or a single DPE. The hospitalization days were significantly longer for patients with multiple DPEs. Conclusion: Pleural effusion accumulates due to continuous inflammation. Although a temporary DPE is sometimes performed, post-operative chest drainage tubes are not necessarily needed.
\end{abstract}

Esophageal cancer (EC) is the sixth leading cause of cancerrelated deaths worldwide. Regarding standard of care, radical esophagectomy remains the main treatment option for localized advanced EC. However, classical esophagectomy is associated with a high risk of postoperative complications and a high mortality rate. Recently, minimally-invasive surgery (MIE), such as laparoscopic or thoracoscopic surgery, has become common in digestive surgery including

Correspondence to: Hirotaka Konishi, MD, Ph.D., Division of Digestive Surgery, Department of Surgery, Kyoto Prefectural University of Medicine, 465 Kajii-cho, Kamigyo-ku, Kyoto 6028566, Japan. Tel: +81 752515527, Fax: +81 752515522, e-mail: h-koni7@koto.kpu-m.ac.jp

Key Words: Esophageal cancer, esophagectomy, pleural effusion, chest drainage, TMrE. the radical esophagectomy for EC. MIE was reported to minimize postoperative pulmonary events, considering the most common postoperative complications (1-3). A transthoracic approach is needed for both conventional open and thoracoscopic esophagectomies, thus the respiratory function can still be affected and complications will be developed. We have performed a trans-hiatal and -cervical mediastinoscopic radical esophagectomy (TMrE) for EC patients without trans-thoracic management in order to reduce pulmonary complications (4).

In the trans-thoracic approach of esophagectomy, drainage tubes are commonly placed into the thoracic cavity to monitor potential bleeding or pneumothorax and drain pleural effusion. However, drainage tubes are not placed in the TMrE, even when the mediastinum pleura is injured. The mediastinal approach of esophagectomy also causes fluid to be collected in the thoracic cavity. Temporary drainages of pleural effusion by puncture of the thoracic cavity are required in some cases.

In the present study, the frequency or treatment of pleural effusions in EC patients that had been treated with $\mathrm{TMrE}$ were investigated. In addition, the relationships between pleural effusion and clinicopathological factors, and the necessity of temporary drainage or tube placement were evaluated.

\section{Patients and Methods}

Patient characteristics. A retrospective analysis of 118 patients having undergone TMrE between 2010 and 2016 at Kyoto Prefectural University of Medicine was conducted. All patients provided informed consent for participation in this retrospective study. Patients and clinicopathological characteristics are described in Table I and include age, gender, body mass index (BMI), tumor location, neoadjuvant therapy, and lymphadenectomy. All patients were diagnosed with squamous cell carcinoma or adenocarcinoma based on surgically resected specimen pathology analysis. Forty-one patients underwent radical esophagectomy without neoadjuvant therapy, 62 patients received neoadjuvant chemotherapy, 1 patient received neoadjuvant chemoradiotherapy, 8 patients underwent 
Table I. Clinicopathological factors between drainage and no-drainage group.

\begin{tabular}{|c|c|c|c|}
\hline & $\begin{array}{l}\text { Drainage } \\
(\mathrm{n}=75)\end{array}$ & $\begin{array}{l}\text { No-drainage } \\
\quad(n=43)\end{array}$ & $p$-Value \\
\hline Age & $68.0(42-87)$ & $66.8(43-84)$ & 0.44 \\
\hline \multicolumn{4}{|l|}{ Gender } \\
\hline Male & 57 & 39 & 0.08 \\
\hline Female & 18 & 4 & \\
\hline BMI & $22.5(12-34)$ & $21.4(14-28)$ & 0.53 \\
\hline FEV1.0\% & $72.0(40-94)$ & $74.2(47-95)$ & 0.29 \\
\hline$\% \mathrm{VC}$ & $100.5(65-145)$ & $103.1(64-130)$ & 0.51 \\
\hline \multicolumn{4}{|c|}{ Tumor location } \\
\hline $\mathrm{Ce} / \mathrm{Ut}$ & $2 / 13$ & $1 / 4$ & 0.36 \\
\hline $\mathrm{Mt} / \mathrm{Lt} / \mathrm{Ae}$ & $33 / 22 / 5$ & $23 / 13 / 2$ & \\
\hline \multicolumn{4}{|c|}{ Neoadjuvant therapy } \\
\hline None & 28 & 13 & 0.97 \\
\hline $\mathrm{CT}$ & 39 & 23 & \\
\hline CRT & 1 & 1 & \\
\hline ESD & 7 & 6 & \\
\hline \multicolumn{4}{|l|}{ cStage } \\
\hline $0 / 1$ & $7 / 14$ & $7 / 8$ & 0.43 \\
\hline $2 / 3 / 4$ & $21 / 30 / 3$ & $12 / 16 / 0$ & \\
\hline \multicolumn{4}{|l|}{$\mathrm{cT}$ factor } \\
\hline 1 & 23 & 19 & 0.20 \\
\hline $2 / 3 / 4$ & $12 / 40 / 0$ & $4 / 20 / 0$ & \\
\hline \multicolumn{4}{|l|}{$\mathrm{cN}$ factor } \\
\hline$(-)$ & 41 & 24 & 0.90 \\
\hline$(+)$ & 34 & 19 & \\
\hline \multicolumn{4}{|c|}{$\begin{array}{l}\text { Fields of lympha- } \\
\text { denectomy }\end{array}$} \\
\hline $1 / 2$ & $1 / 65$ & $0 / 38$ & 0.81 \\
\hline 3 & 9 & 5 & \\
\hline \multicolumn{4}{|l|}{ pStage } \\
\hline $0 / 1$ & $15 / 12$ & $12 / 7$ & 0.38 \\
\hline $2 / 3 / 4 a$ & $27 / 20 / 1$ & $9 / 13 / 2$ & \\
\hline \multicolumn{4}{|l|}{ pT factor } \\
\hline $0 / 1$ & $2 / 38$ & $3 / 20$ & 0.98 \\
\hline $2 / 3 / 4$ & $8 / 27 / 0$ & $2 / 17 / 1$ & \\
\hline \multicolumn{4}{|l|}{$\mathrm{pN}$ factor } \\
\hline$(-)$ & 42 & 24 & 0.40 \\
\hline$(+)$ & 33 & 19 & \\
\hline \multicolumn{4}{|l|}{ ly } \\
\hline$(+)$ & 33 & 21 & 0.61 \\
\hline$(-)$ & 42 & 22 & \\
\hline \multicolumn{4}{|l|}{$\mathrm{v}$} \\
\hline$(+)$ & 30 & 20 & 0.49 \\
\hline$(-)$ & 45 & 23 & \\
\hline
\end{tabular}

BMI: Body mass index; FEV1.0\%: forced expiratory volume $1.0 \mathrm{sec} \%$; \%VC: \% vital capacity; CT: chemotherapy; CRT: chemoradiotherapy; ESD: endoscopic submucosal dissection.

endoscopic submucosal dissection (ESD) followed by radical esophagectomy, and 1 patient received definitive chemoradiotherapy followed by salvage esophagectomy. All patients received subtotal radical esophagectomy with lymph node dissection and reconstruction was performed using gastric or ileocolic tube. Fourteen patients underwent three-fields lymphadenectomy, and 104
Table II. Intra- and post-operative factors between drainage and nodrainage group.

\begin{tabular}{|c|c|c|c|}
\hline & $\begin{array}{c}\text { Drainage } \\
(\mathrm{n}=75)\end{array}$ & $\begin{array}{l}\text { No-drainage } \\
\quad(n=43)\end{array}$ & $p$-Value \\
\hline Operation time (min, mean) & 328 & 332 & 0.53 \\
\hline Bleeding ( $\mathrm{g}$, mean) & 251 & 200 & 0.31 \\
\hline \multicolumn{4}{|l|}{ CRP (mg/dl, mean) } \\
\hline POD1 & 8.06 & 8.06 & 0.52 \\
\hline POD3 & 16.84 & 15.14 & 0.30 \\
\hline POD5 & 10.51 & 9.23 & 0.20 \\
\hline \multicolumn{4}{|l|}{$\mathrm{Alb}(\mathrm{g} / \mathrm{dl}$, mean $)$} \\
\hline POD1 & 2.89 & 2.93 & 0.23 \\
\hline POD3 & 2.78 & 2.78 & 0.53 \\
\hline POD5 & 2.86 & 2.78 & 0.52 \\
\hline \multicolumn{4}{|l|}{$\operatorname{WBC}(\mu 1$, mean $)$} \\
\hline POD1 & 9.40 & 8.42 & 0.30 \\
\hline POD3 & 8.98 & 8.52 & 0.51 \\
\hline POD5 & 7.99 & 7.84 & 0.52 \\
\hline \multicolumn{4}{|l|}{ Anastomotic leakage } \\
\hline$(+)$ & 61 & 39 & 0.27 \\
\hline$(-)$ & 14 & 4 & \\
\hline \multicolumn{4}{|l|}{ Pulmonary complication } \\
\hline$(+)$ & 64 & 38 & 0.85 \\
\hline$(-)$ & 11 & 5 & \\
\hline \multicolumn{4}{|l|}{ Resection of thoracic duct } \\
\hline$(+)$ & 5 & 0 & 0.21 \\
\hline$(-)$ & 70 & 43 & \\
\hline Length of hospital stay & 44.2 & 41.3 & 0.09 \\
\hline
\end{tabular}

CRP: C-reactive protein; Alb: albumin; WBC: white blood cell.

patients underwent two-fields lymphadenectomy in accordance with patient and tumor status.

Follow-up examination after surgery. All patients underwent extubation just after surgery and the movements of their vocal cord were immediately evaluated. All patients received care in the intensive care unit the first night and were transferred to general ward in the morning if they were in a stable condition. Patients were allowed to walk the day after surgery. Blood tests and chest X-rays were performed every day for a week after surgery, and ultrasonography was performed if pleural effusion was suspected.

Drainage of pleural effusion (DPE). Drainage of pleural effusion (DPE) was performed under local anesthesia. Pleural effusion was drained as much as possible by single aspiration, and patients received additional DPEs as needed. A chest tube was placed for the second or any later drainage at the attending physician's judgment.

Statistical analysis. All statistical analyses were performed using the Stat View 5.0 J software program. The chi-squared test was used to analyse potential relationships between clinicopathological features and DPE frequency. The Mann-Whitney $U$ test was used to analyse potential associations between clinical data and DPE frequency. A $p$-value less than 0.05 was considered significant. 
Table III. Drainage-related factors of left-and right-side drainage.

\begin{tabular}{|c|c|c|c|c|}
\hline & \multirow[t]{2}{*}{ Total } & \multicolumn{2}{|c|}{ Drainage side } & \multirow[t]{2}{*}{$p$-Value } \\
\hline & & Left & Right & \\
\hline Number of patients with drainage & 75 & 60 & 43 & 0.003 \\
\hline Total number of drainages & 144 & 84 & 60 & \\
\hline Frequency of drainage & 1.9 & 1.4 & 1.4 & \\
\hline \multicolumn{5}{|c|}{ Initial days of drainage after operation (mean) } \\
\hline $1 \mathrm{st}$ & 3.4 & 3.1 & 3.8 & 0.28 \\
\hline 2nd & 4.9 & 4.6 & 5.4 & 0.39 \\
\hline $3 r d$ & 9.8 & 10 & 9.5 & 0.54 \\
\hline \multicolumn{5}{|l|}{ Volume of drainage ( $\mathrm{ml}$, mean) } \\
\hline $1 \mathrm{st}$ & 555 & 560 & 549 & 0.52 \\
\hline 2nd & 675 & 602 & 748 & 0.22 \\
\hline $3 r d$ & 568 & 475 & 660 & 0.61 \\
\hline
\end{tabular}

\section{Results}

Drainage of pleural effusion (DPE) was performed in 75 patients (64\%, drainage group), while 43 patients did not receive any DPE (36\%, non-drainage group). There were no significant differences between the two groups in terms of clinicopathological characteristics including pre-operative respiratory function (Table I), or operation-related factors and laboratory data (Table II). The hospital stay was slightly longer for the drainage group $(p=0.09)$. The details of DPE are shown in Table III and Figure 1. Most patients in the drainage group underwent DPE once or twice $(56 / 75,75 \%)$. A single DPE was the most common $(34 / 75,45 \%)$, while over 3 DPEs were uncommon $(4 / 75 ; 5 \%)$. Twenty-eight patients underwent DPEs on both sides (Figure 1). Left side drainage was significantly frequent compared to that of the right side (60 versus 43 cases, $p=0.003$, Table III). The average frequency of DPEs in the drainage group was 1.9 times (range $=1-7$ times), and left-side and right-side drainages were both performed 1.4 times. The first DPE was performed on average post-operative day (POD) 3.4 (range=POD1-15), the second DPE on POD 4.9 (range=POD2-11), and the third DPE on POD 9.8 (range $=$ POD3-15). There were no significant differences in the initial day of drainage after operation or in the volume of DPE between left and right sides.

Change in CRP levels compared with that at POD1 was examined between patients with single and multiple DPEs (Figure 2A). Fold increase in CRP levels was significantly higher in the patients with multiple DPEs than in patients with a single DPE in POD3 $(p=0.02)$. The same trend was confirmed in POD5 $(p=0.06)$. The CRP level change was similar in patients having received a single DPE and no DPE (Figure 2B). Table IV shows the clinicopathological features of patients with no or a single DPE compared with those with

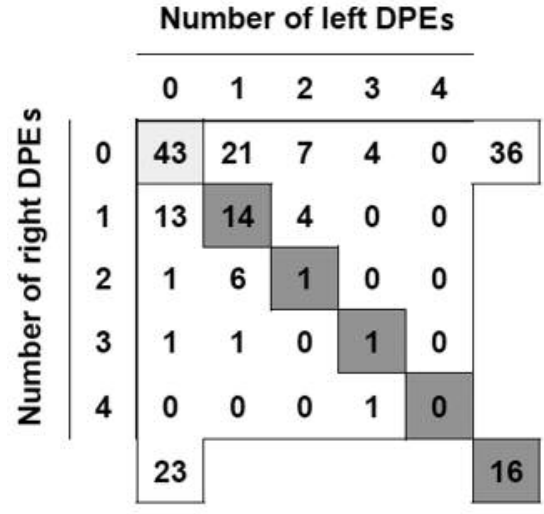

Figure 1. Number of patients who underwent left and/or right DPEs. Overall, 43 patients did not require DPE and 16 patients required left and right DPE at same frequency. A total of 36 patients required left $D P E$ more frequently than right DPE, and 23 patients required right DPE more frequently than left DPE.

multiple DPEs. The clinicopathological factors were not statistically different among these patients. However, the preoperative respiratory function was slightly inferior in the patients with multiple DPEs ( $p=0.06$, Table IV). Postoperative complications, such as pulmonary complication $(p=0.17)$ or anastomotic leakage $(p=0.14)$, and the volume of operative bleeding $(p=0.06)$ also tended to relate with multiple DPEs. Thoracic duct was resected in 5 patients due to tumor progression (Table II), and all of them needed DPE. However, multiple DPEs were not always needed in these 5 patients $(p=0.46$, Table IV). The hospitalization days were significantly longer for patients with multiple DPEs than those without multiple DPEs (53.1 days versus 37.9 days, $p<0.001$ ).

In subgroup analyses among the 85 patients without postoperative complications, no significant differences were 
A

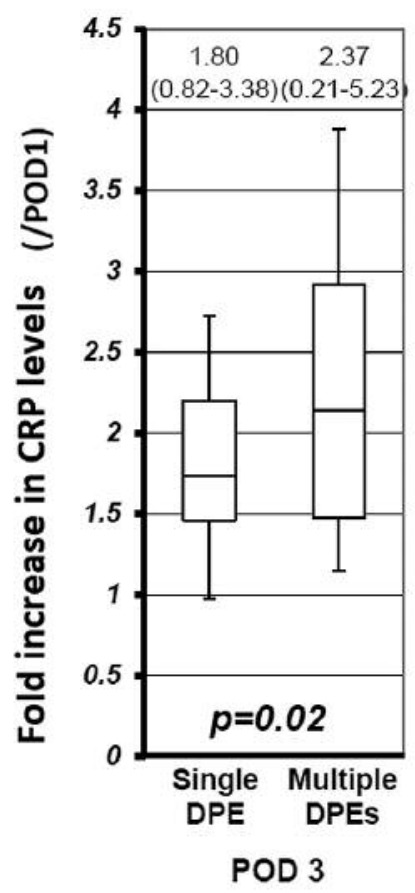

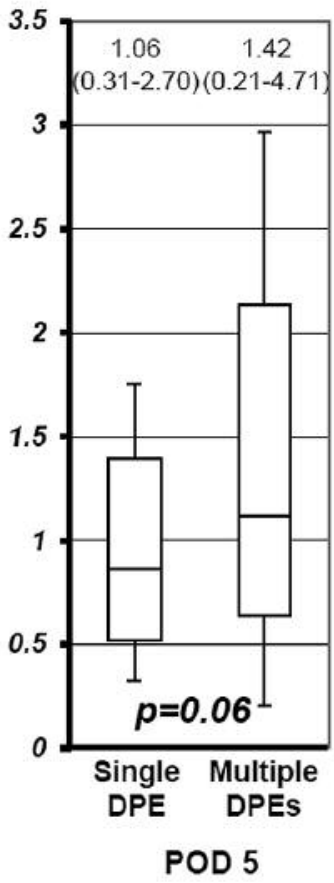

B

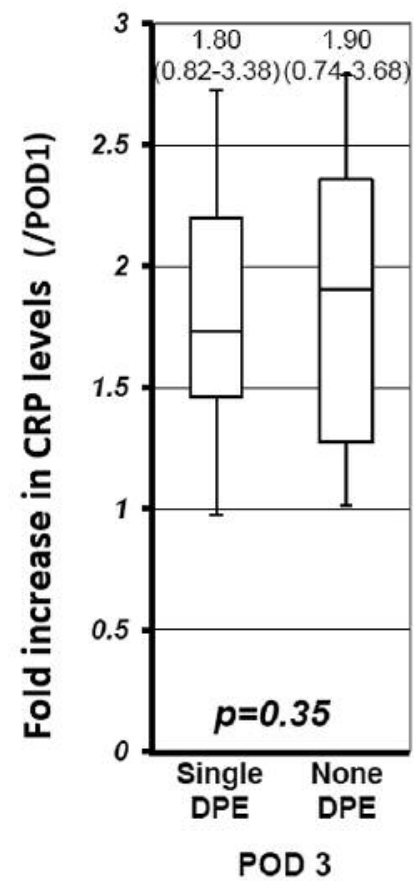

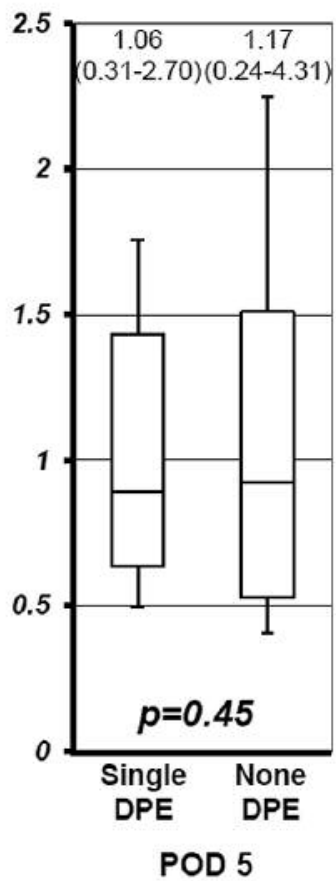

Figure 2. Comparisons of changes in CRP levels are shown among each group by the boxplots. The average and range of changes in the values are indicated on the upper side of schema. A. The fold increase in CRP levels in patients with single DPE and multiple DPEs on POD3 and POD5 compared to POD1. B: The fold increase in CRP levels between the patients with single DPE and none DPE on POD3 and POD5 compared to POD1.

found in the fold increase of CRP levels between the none or single DPE group and the multiple DPEs group (Figure $3 \mathrm{~A})$. However, respiratory function $(\% \mathrm{VC})$ in the none or single DPEs group was better than that in the multiple DPEs group (Figure 3B).

Drainage tubes were placed in only 6 patients due to massive pleural effusion or frequent DPEs (Table V); two patients required drainage tubes at both sides, three patients at the right side, and one patient at the left side. Tracheal injury, pneumothorax, chylothorax, or frequent DPEs were the reasons for requiring continuous drainage. Only one patient underwent thoracic duct resection out of these six patients.

\section{Discussion}

Radical esophagectomy for EC implies an operation region ranging from the neck to the abdominal cavity and this surgery has a high mortality rate (5). Recently, minimally invasive surgery (MIE), such as laparoscopic or thoracoscopic surgery, has become common in digestive surgery including the radical esophagectomy for EC (1, 6, 7). Although MIE is lessinvasive and feasible for radical esophagectomy, its safety needs to be further investigated. The trans-thoracic approach management is also needed in MIE, and we consider that this approach will affect respiratory functions and cause some complications. Therefore, a trans-hiatal and -cervical mediastinoscopic radical esophagectomy (TMrE) without trans-thoracic management may represent the most minimally invasive surgery for EC patients.

It is common practice to place drainage tubes into the thoracic cavity for the trans-thoracic approach esophagectomy. On the other hand, a thoracic drainage tube is not commonly placed in TMrE because the thoracic cavity is not opened and the lung is not collapsed. However, some patients suffer from pleural effusion and require DPE to improve their respiratory status. In the present study, we retrospectively examined the incidence of pleural effusion after TMrE, and showed the change in CRP levels as an indicator of DPE. A chest X-ray revealed that pleural effusion accumulated in almost all patients. However, while $64 \%$ of patients underwent DPE after TMrE, $36 \%$ did neither have a drainage tube nor DPE and had no disadvantage in the postoperative course.

Recent studies have demonstrated an association between increased inflammation and pleural effusion $(8,9)$. Pleural 
Table IV. Clinicopathological factors of the patients with none or once DPE and multiple DPEs.

\begin{tabular}{|c|c|c|c|}
\hline & $\begin{array}{c}\text { None or one DPE } \\
(\mathrm{n}=77)\end{array}$ & $\begin{array}{l}\text { Multiple DPEs } \\
\qquad(\mathrm{n}=41)\end{array}$ & $p$-Value \\
\hline Age & 67.2 & 68.1 & 0.27 \\
\hline \multicolumn{4}{|l|}{ Gender } \\
\hline Male & 65 & 31 & \multirow[t]{2}{*}{0.24} \\
\hline Female & 12 & 10 & \\
\hline$\% \mathrm{VC}$ & $102.8(73.2-144.8)$ & $97.5(65-130.7)$ & 0.06 \\
\hline FEV $1.0 \%$ & 73.5 & 71.4 & 0.22 \\
\hline \multicolumn{4}{|l|}{ Tumor location } \\
\hline $\mathrm{Ce} / \mathrm{Ut}$ & 13 & 11 & \multirow{2}{*}{0.20} \\
\hline $\mathrm{Mt} / \mathrm{Lt} / \mathrm{Ae}$ & 64 & 30 & \\
\hline \multicolumn{4}{|l|}{ Neoadjuvant therapy } \\
\hline None & 23 & 18 & \multirow[t]{2}{*}{0.13} \\
\hline $\mathrm{CT} / \mathrm{CRT} / \mathrm{ESD}$ & 54 & 23 & \\
\hline \multicolumn{4}{|l|}{ pStage } \\
\hline $0 / 1$ & 31 & 15 & \multirow[t]{2}{*}{0.70} \\
\hline $2 / 3 / 4$ & 46 & 26 & \\
\hline \multicolumn{4}{|l|}{ pT factor } \\
\hline $0 / 1$ & 39 & 24 & \multirow[t]{2}{*}{0.36} \\
\hline $2 / 3 / 4$ & 38 & 16 & \\
\hline \multicolumn{4}{|l|}{$\mathrm{pN}$ factor } \\
\hline$(-)$ & 41 & 25 & \multirow[t]{2}{*}{0.42} \\
\hline$(+)$ & 36 & 16 & \\
\hline \multicolumn{4}{|l|}{ Fields of lymphadenectomy } \\
\hline $1 / 2$ & 67 & 37 & \multirow[t]{2}{*}{0.83} \\
\hline 3 & 10 & 4 & \\
\hline Operation time (min, mean) & 330 & 329 & 0.49 \\
\hline Bleeding $(\mathrm{g}$, mean $)$ & 215.5 & 264.1 & 0.06 \\
\hline \multicolumn{4}{|l|}{ Fold increase in CRP (/POD1) } \\
\hline POD3 & 1.85 & 2.37 & 0.01 \\
\hline POD5 & 0.99 & 1.42 & 0.02 \\
\hline \multicolumn{4}{|l|}{ Anastomotic leakage } \\
\hline$(+)$ & $9(12 \%)$ & $9(22 \%)$ & \multirow[t]{2}{*}{0.14} \\
\hline$(-)$ & $68(88 \%)$ & $32(78 \%)$ & \\
\hline \multicolumn{4}{|l|}{ Pulmonary complication } \\
\hline$(+)$ & $8(10 \%)$ & $8(20 \%)$ & \multirow[t]{2}{*}{0.17} \\
\hline$(-)$ & $69(90 \%)$ & $33(80 \%)$ & \\
\hline \multicolumn{4}{|l|}{ Resection of thoracic duct } \\
\hline$(+)$ & 2 & 3 & \multirow[t]{2}{*}{0.46} \\
\hline$(-)$ & 75 & 38 & \\
\hline Length of hospital stay & 37.9 & 53.1 & $<0.001$ \\
\hline
\end{tabular}

FEV1.0\%: Forced expiratory volume $1.0(\mathrm{sec}) \%$; CT: chemotherapy; CRT: chemoradiotherapy; ESD: endoscopic submucosal dissection; CRP: Creactive protein; POD: post-operative day.

effusions after esophagectomy frequently accumulate at the left side, because the esophagus is located at the left side of the mediastinum and esophagectomy with lymphadenectomy induce inflammation mainly to the left side of the mediastinum. In the present study, pleural effusion was found to be frequently accumulated in the left thoracic cavity compared to the right side. Moreover, the relationship between the changes in CRP levels and DPE suggests that inflammation plays a role in producing pleural effusion. The fold increase in CRP levels in day 3 or 5 were higher in patients with multiple DPEs (10). Regarding inflammation, postoperative complications, such as anastomotic leakage or pulmonary complication, were slightly associated with multiple DPEs, likely leading to longer hospital stays.

Poor respiratory function represents a risk factor influencing the drainage volume of pleural effusion (11). In the present study, the respiratory function of patients without post-operative complications was better in the patients with none or single DPEs. This result suggests that patients with poor respiratory function, especially lower \%VC, may require multiple DPEs after TMrE even in the absence of trans-thoracic management. 
A

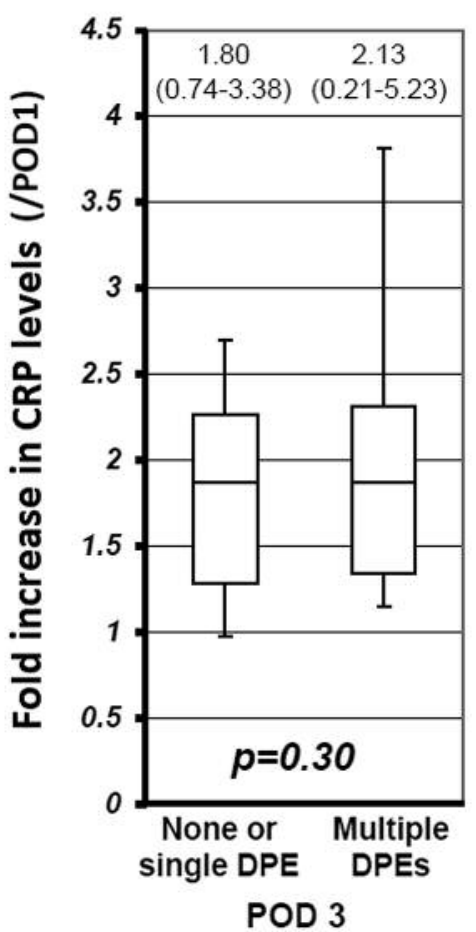

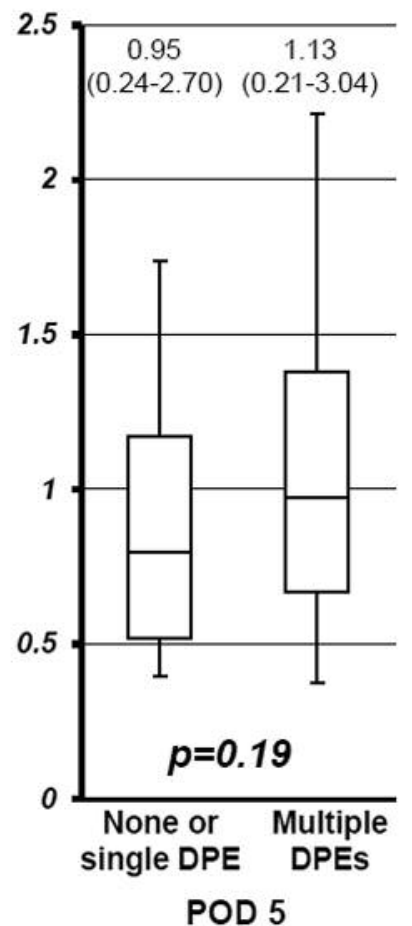

B

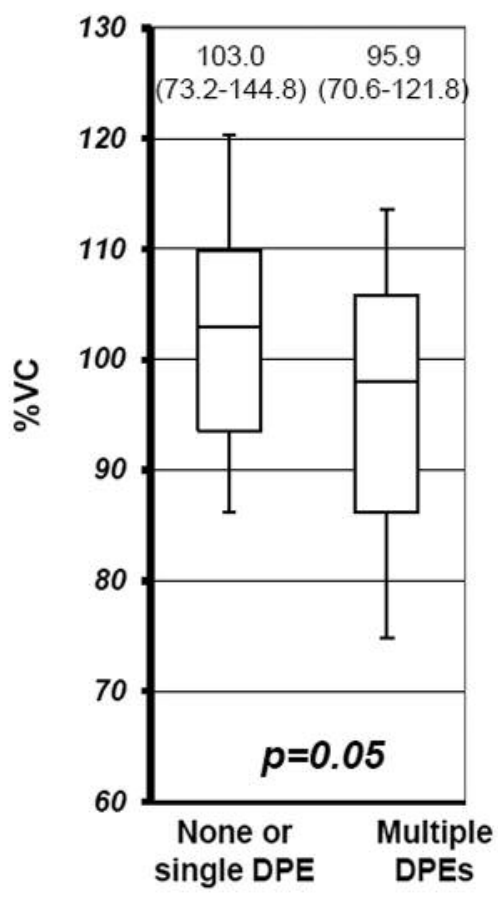

Figure 3. Comparisons of changes in CRP value and respiratory function (\%VC) between the none or single DPE group and the multiple DPEs group are shown in patients without post-operative complications. The data are shown by the boxplots, and the average and range of of changes are indicated on the upper side of schema. A: The of the fold increase in CRP levels on POD3 and POD5 compared to POD1. B: The results of pre-operative respiratory function $(\% \mathrm{VC})$.

Table V. Details of patients who required continuous chest drainage tube.

\begin{tabular}{|c|c|c|c|c|c|c|c|c|}
\hline \multirow[t]{2}{*}{ Patient number } & \multirow[t]{2}{*}{ Age } & \multirow[t]{2}{*}{ Gender } & \multirow[t]{2}{*}{$\% \mathrm{VC}$} & \multirow{2}{*}{$\begin{array}{c}\text { Neoadjuvant } \\
\text { therapy }\end{array}$} & \multirow{2}{*}{$\begin{array}{l}\text { Frequency of } \\
\text { drainage }\end{array}$} & \multicolumn{3}{|c|}{ Chest tubes } \\
\hline & & & & & & Side & POD (left) & POD (right) \\
\hline 1 & 55 & M & 114 & ESD & 1 & Left & 0 & $(-)$ \\
\hline 2 & 74 & M & 78.2 & None & 3 & RIght & $(-)$ & 7 \\
\hline 3 & 70 & $\mathrm{~F}$ & 65 & None & 4 & Right & $(-)$ & 12 \\
\hline 4 & 73 & M & 129 & $\mathrm{CT}$ & 2 & Right & $(-)$ & 24 \\
\hline 5 & 74 & M & 89 & CT & 3 & Both & 2 & 3 \\
\hline 6 & 70 & M & 90.4 & $\mathrm{CT}$ & 3 & Both & 5 & 4 \\
\hline $\begin{array}{l}\text { Total drained } \\
\text { volume (left) (ml) }\end{array}$ & \multicolumn{3}{|c|}{$\begin{array}{c}\text { Total drainaged } \\
\text { volume (right) }(\mathrm{ml})\end{array}$} & $\begin{array}{c}\text { Thoracic } \\
\text { duct }\end{array}$ & $\begin{array}{l}\text { Anastomotic } \\
\text { leakage }\end{array}$ & \multicolumn{2}{|c|}{$\begin{array}{l}\text { Pulmonary } \\
\text { complication }\end{array}$} & Others \\
\hline Unknown & & 0 & & Preserved & $(-)$ & \multicolumn{2}{|c|}{$(+)$} & Tracheal injury \\
\hline 600 & & 1050 & & Resected & $(+)$ & \multicolumn{2}{|c|}{$(-)$} & \\
\hline 550 & & 1130 & & Preserved & $(+)$ & \multicolumn{2}{|c|}{$(-)$} & \\
\hline 430 & & 300 & & Preserved & $(-)$ & \multicolumn{2}{|c|}{$(+)$} & Pneumothorax \\
\hline 1000 & & 2000 & & Preserved & $(-)$ & \multicolumn{2}{|c|}{$(-)$} & Chylothorax \\
\hline 1100 & & 1000 & & Preserved & $(-)$ & \multicolumn{2}{|c|}{$(+)$} & \\
\hline
\end{tabular}

\%VC: \% Vital capacity; POD: post-operative day; ESD: endoscopic submucosal dissection; CT: chemotherapy. 
Reports are proposing best practices when using routine drainage tubes after gastrointestinal surgery on the basis of the enhanced recovery after surgery (ERAS). In particular, dispensable insertional objects should be avoided and if really required, they should be removed from patients as early as possible (12-14). In the present study, routine chest drainage tube was not placed and was not necessarily required after TMrE, because 77 patients $(65 \%)$ underwent no or only a single DPE. However, a higher post-operative CRP level or poor respiratory status may cause massive and continuous pleural effusion and would require frequent DPEs. Patients presenting with these factors should be observed carefully for pleural effusion after TMrE and DPEs should not be hesitated.

The main limitation of this study was that the diagnosis of pleural effusion and necessity of DPE were under the responsibility of the attending physician. Therefore, biases in the requirement of DPE or placement of thoracic tubes cannot be excluded. During the TMrE procedure, the mediastinal pleura is sometimes injured by accident or resected due to tumor progression. In these cases, the mediastinal pleura defect might influence the mediastinal inflammation or DPE requirement despite the absence of a trans-thoracic approach. However, we consider it might not greatly affect pleural effusion because a defect in mediastinal pleura would prompt a drainage of pleural effusion from the mediastinal side.

In conclusion, pleural effusion accumulates in patients performing mediastinoscopic radical esophagectomy due to continuous inflammation. Although temporary drainage of pleural effusion is sometimes performed, chest drainage tubes are not necessarily needed.

\section{References}

1 Luketich JD, Alvelo-Rivera M, Buenaventura PO, Christie NA, McCaughan JS, Litle VR, Schauer PR, Close JM and Fernando HC: Minimally invasive esophagectomy: Outcomes in 222 patients. Ann Surg 238(4): 486-494, 2003

2 Nafteux P, Moons J, Coosemans W, Decaluwé H, Decker G, De Leyn P, Van Raemdonck D and Lerut T: Minimally invasive oesophagectomy: A valuable alternative to open oesophagectomy for the treatment of early oesophageal and gastro-oesophageal junction carcinoma. Eur J Cardiothorac Surg 40(6): 1455-1463, 2011.

3 Tsujimoto H, Takahata R, Nomura S, Yaguchi Y, Kumano I, Matsumoto Y, Yoshida K, Horiguchi H, Hiraki S, Ono S, Yamamoto $\mathrm{J}$ and Hase K: Video-assisted thoracoscopic surgery for esophageal cancer attenuates postoperative systemic responses and pulmonary complications. Surgery 151(5): 667-673, 2012.
4 Takeuchi $\mathrm{H}$, Miyata H, Ozawa S, Udagawa H, Osugi $\mathrm{H}$, Matsubara H, Konno H, Seto Y and Kitagawa Y: Comparison of short-term outcomes between open and minimally invasive esophagectomy for esophageal cancer using a nationwide database in Japan. Ann Surg Oncol 24(7): 1821-1827, 2017.

5 Talsma AK, Lingsma HF, Steyerberg EW, Wijnhoven BP and Van Lanschot JJ: The 30-day versus in-hospital and 90-day mortality after esophagectomy as indicators for quality of care. Ann Surg 260(2): 267-273, 2014.

6 Luketich JD, Pennathur A, Franchetti Y, Catalano PJ, Swanson S, Sugarbaker DJ, De Hoyos A, Maddaus MA, Nguyen NT, Benson $\mathrm{AB}$ and Fernando HC: Minimally invasive esophagectomy: results of a prospective phase II multicenter trial-the eastern cooperative oncology group (E2202) study. Ann Surg 261(4): 702-707, 2015.

7 Fujiwara H, Shiozaki A, Konishi H and Otsuji E: Mediastinoscope and laparoscope-assisted esophagectomy. J Visualized Surg 2: 125, 2016.

8 Szczesny TJ, Slotwinski R, Stankiewicz A, Szczygiel B, Zaleska $\mathrm{M}$ and Kopacz M: Interleukin 6 and interleukin 1 receptor antagonist as early markers of complications after lung cancer surgery. Eur J Cardiothorac Surg 31(4): 719-724, 2007.

9 Takenaka K, Ogawa E, Wada $\mathrm{H}$ and Hirata T: Systemic inflammatory response syndrome and surgical stress in thoracic surgery. J Critical Care 21(1): 48-53, 2006.

10 Cabellos Olivares M, Labalde Martinez M, Torralba M, Rodriguez Fraile JR and Atance Martinez JC: C-reactive protein as a marker of the surgical stress reduction within an ERAS protocol (Enhanced Recovery After Surgery) in colorectal surgery: A prospective cohort study. J Surg Oncol 117: 717-724, 2018.

11 Kosugi S, Kanda T, Yajima K, Ishikawa T and Sakamoto K: Risk factors influencing the pleural drainage volume after transthoracic oesophagectomy. Eur J Cardiothorac Surg 43(6): 1116-1120, 2013.

12 Ishikawa K, Matsumata T, Kishihara F, Fukuyama Y and Masuda H: Laparoscopy-assisted distal gastrectomy for early gastric cancer with versus without prophylactic drainage. Surg Today 41(8): 1049-1053, 2011.

13 Wang Q, Jiang YJ, Li J, Yang F, Di Y, Yao L, Jin C and Fu DL: Is routine drainage necessary after pancreaticoduodenectomy? World J Gastroenterol 20(25): 8110-8118, 2014.

14 Yao F, Wang J, Yao J, Hang F, Cao S, Qian J and Xu L: Early chest tube removal after thoracoscopic esophagectomy with high output. J Laparoendosc Adv Surg Tech A 26(1): 17-22, 2016.

Received October 25, 2018

Revised November 8, 2018

Accepted November 9, 2018 